\title{
A NARX model to Predict Cabin Air Temperature to ameliorate HVAC Functionality
}

\author{
Srikanth Kolachalama, Hafiz Malik \\ Electrical and Computer Engineering, University of Michigan, Dearborn 48128, USA \\ Corresponding author: skola@umich.edu; Co-author: hafiz@umich.edu
}

\begin{abstract}
The vehicular technology has integrated many features in the system, which enhances the safety and comfort of the user. Among these features, heating, ventilation, and air conditioning (HVAC) is the only feature that maintains the set cabin air temperature (CAT). The user's command drives the set CAT, and the thermostat provides feedback to the HVAC to maintain the set CAT. The CAT is increased by extracting the heat from the engine surface produced by the fuel combustion, whereas the CAT is reduced by the known processes of the air conditioning system (ACS). Therefore, the CAT driven by the user's command may not be optimal, and estimating the optimal CAT is still unsolved. In this work, the user was allowed to input a range for CAT instead of a single value. Optimal HVAC criteria were defined, and the CAT was estimated by performing iterative analysis in the user-selected range satisfying the criteria. The HVAC criteria were defined based on two measurable parameters: air conditioning refrigerant fluid pressure (ACRFP) and engine surface temperature (EST) empirically defined as the vector CATOP. In this article, a NARX DL model by mapping the vehicle-level vectors (VLV) to predict the CATOP in real-time using field data obtained from a 2020 Cadillac CT5 test vehicle. Utilising the DL model, CATOP for future time steps were predicted by varying the CAT in the definite range and applying HVAC criteria. Thus, an optimal set CAT was estimated, corresponding to the optimal CATOP defined by the HVAC criteria. We performed the validation of the DL model for multiple datasets using traditional statistical techniques, namely, signal-to-noise ratio (SNR) values, first-order derivatives (FOD), and root-mean-square error (RMSE).
\end{abstract}

KEYWORDS: Deep Learning, HVAC, Cabin Air Temperature, Driver Behavior, NARX.

\section{Introduction}

The automotive industry's evolution has influenced every engineering aspect, including materials science, thermal engineering, and control theory [1]. In an internal combustion engine driven vehicle, the thermal energy produced by the combustion process is exchanged between the ambience, engine components, HVAC, lubrication oil, and coolant [2]. HVAC is the only module integrated into the vehicle functions to maintain the CAT set by the user, and in this article, we propose a novel methodology to predict the set CAT. It is known from the existing literature [6] that the CAT is reduced by the ACS [3] and increased by extracting heat from the engine surface [4-5].

Reference [7] adopted an adaptive control technique to alter the functioning of the ACS based on environmental conditions and driver behaviour. This method produced simulation results that project $1 \%$ more energy-saving than the conventional fuzzy logic control used by reference [8]. The fuzzy logic control developed in [8] contained an iterative analysis of CAT and the ACS compressor load to evaluate the system's performance, including reduced energy consumption [8]. Reference [9] developed an ACS to produce a desirable CAT and maintain the air quality in conjunction with the engine controller by activating cruise control. References [10]-[11] investigated the parameters of the mass flow rate of the air by dynamically adjusting the blower speed and air-gates opening under various thermal loads, which resulted in reduced energy consumption. Reference [12] developed a heat balance method for estimating the thermal load encountered by the cabin using a predictive model mapping the driving conditions. This method could potentially predict thermal comfort in real-time and thus reduce the power consumption of the ACS. Finally, reference [13] developed an optimised control model for three stages to enhance the efficiency of the ACS. These stages include optimising the ACS operating point based on the control inputs and relevant actuators. All the models developed to optimise the HVAC system have automated functionality and do not involve the user's input. Also, none of the existing literature proposed a model that can generate a unique CAT driven by the user's command to augment the HVAC efficiency. In this article, we propose a method to predict the CAT in a definite range defined by the user (e.g., [65 70] ${ }^{\circ} \mathrm{F}$ during summers and $[7075]^{\circ} \mathrm{F}$ during winters).

In reference [14], we developed a novel DL model using NARX and LSTM techniques to predict EOP with VLV as inputs. The VLV shall consist of the elements [Vehicle age, DBV, Environment factors, Body module parameters]. The results depict that the NARX DL model best predicted EOP and utilizing this technique we developed a computational iterative model to predict ACCSSP [28]. Inspired by the above research [14] [28], a similar NARX DL model was developed, mapping the elements VLV - [Odometer, DBV, EAT] and CATOPEST and ACRFP (HVAC). CATOP is an empirical parameter defined to represent the HVAC elements, and optimal HVAC criteria are defined and applied to the predicted CATOP in real-time. We estimated a unique 
CAT value by analysing these results, and the detailed procedure adopted is shown in the following sections. The rest of the article is organised as follows: Section 2 and 4 propose predicting CATOP and CAT, whereas Section 3 defines the HVAC criteria applied to the CATOP to generate an optimal CAT profile. In Section 5, the detailed results of the predictive model and experimental techniques are presented.

\section{Predictive Model-CATOP}

We discuss the NARX DL model elements to predict CATOP - ACRFP and EST in this section.

\subsection{Modeling}

The NARX DL model is developed mapping the VLV [Time step, Odometer, DBV, EAT] and CATOP — [EST, ACRFP] with default training properties [15]. The DBV is defined with five parameters [Speed, YAR, LAT, LOT, CAT], which are the user's prerogative in real-time [28]. The parameters EAT and CAT influence thermal stress on the engine [16], whereas the odometer reading reflects the age of the vehicle. The remaining VLV elements [vehicle posture, aerodynamics, tire pressure] are not considered in the project as their effects are assumed to be insignificant [17]. Also, the orientation of the RRC vector is insignificant for the analysis; thus, positive values of LAT and YAR are considered in developing the DL models. The purpose of selecting EST and ACRFP as outputs and methodology to develop the DL models are discussed in section 3 [18] and section 5.2.

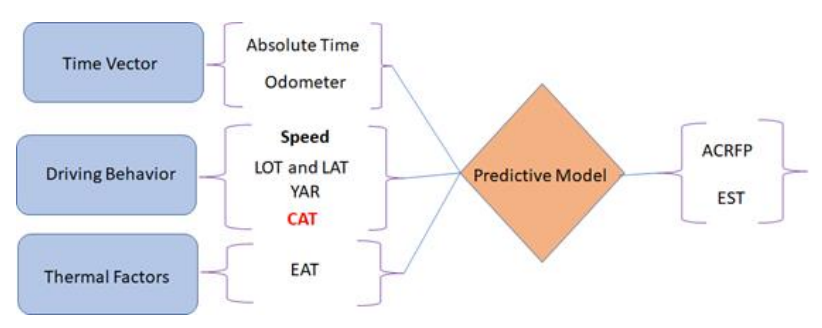

Fig. 1 : NARX DL Model—Inputs and Outputs. [28]

\section{Optimal CATOP Criteria}

In the existing literature, researchers optimised the HVAC system by applying the constraint of fuel economy [23]. However, the experimental results show that this analysis has resulted in the percentage of fuel saved per trip is < $2 \%$. Deviating from the traditional concept of optimising fuel economy, two parameters, EST ( $\left.{ }^{\circ} \mathrm{F}\right)$ and ACRFP (PSI), that reflect HVAC performance, were identified. The only external input to the vehicle is the fuel-air mixture, which produces thermal energy through combustion phenomena. EST is maintained in a specific range by transferring heat to four main elements-engine oil, cabin, coolant/radiator, and external ambience [24].
Similarly, the ACS functionality is affected by multiple parameters, including compressor load, engine fan speed, and power consumed. However, by analysing the real-time test data, we conclude that variations of these parameters were insignificant due to minor changes in CAT $\left({ }^{\circ} \mathrm{F}\right)$. Hence, the parameter ACRFP was considered the CATOP element, which showed substantial fluctuations by varying EAT $\left({ }^{\circ} \mathrm{F}\right)$ and CAT $\left({ }^{\circ} \mathrm{F}\right)$.

\subsection{CATOP element - EST}

It is known from the existing literature that optimal thermal stress on the engine components and ideal engine oil viscosity is achieved when $\mathrm{EST}=90^{\circ} \mathrm{C}\left(194{ }^{\circ} \mathrm{F}\right)$ [24] [25]. Hence, the minimum magnitude value of the conformance between the predicted EST $\left(E S T_{p}\right)$ and ideal EST $\left(E S T_{i}=90{ }^{\circ} \mathrm{C}\right)$ is desired for optimal HVAC functionality. The real-time test data depict that EST $\left({ }^{\circ} \mathrm{F}\right)$ recorded was observed in the range of $[165220]^{\circ} \mathrm{F}$.

Hence, we define two empirical parameters [A1 A2] to split the scenarios representing the cases when the predicted EST $\left(E S T_{p}\right)>90{ }^{\circ} \mathrm{C}$ and $<90{ }^{\circ} \mathrm{C}$. The parameters [A1 A2] are plotted for the snippet of the test case $(1 \mathrm{Km})$, and the area under the curve is evaluated [Area_A1, Area_A2]. Hence, the minimum value of the parameters [Area_A1, Area_A2] is considered the criteria reflecting optimal $\mathrm{HVAC}$ for the element $\operatorname{EST}\left({ }^{\circ} \mathrm{F}\right)$.

$$
\begin{aligned}
& A 1=\left(E S T_{p}-E S T_{i}\right), \text { if } E S T_{p}>E S T_{i}=90^{\circ} \mathrm{C} . \\
& A 1=0, \text { if } E S T_{p}<E S T_{i}=90^{\circ} \mathrm{C}=194^{\circ} \mathrm{F} . \\
& A 2=\left(E S T_{i}-E S T_{p}\right), \text { if } E S T_{p} \leq E S T_{i}=90^{\circ} \mathrm{C} . \\
& A 2=0, \text { if } E S T_{p} \geq E S T_{i}=90^{\circ} \mathrm{C}=194^{\circ} \mathrm{F} .
\end{aligned}
$$

\subsection{CATOP element - ACRFP}

The ACS of the test vehicle was assumed to function with the refrigerant R134a. The ideal functioning of the ACS was defined by correlating the upper boundary limits of the ACRFP for the corresponding EAT [26]. We show these values in Figure 2, and the intermittent higher boundary values of ACRFP (PSI) for EAT $\left({ }^{\circ} \mathrm{F}\right)$ in the range $\left[\begin{array}{ll}65 & 110\end{array}{ }^{\circ} \mathrm{F}\right.$ could be estimated by basic linear interpolation. Hence, an empirical parameter B (PSI) is defined, representing the conformance of the predicted $A C R F P_{p}$ and threshold $A C R F P_{h}$. The threshold $A C R F P_{h}$ is estimated by correlating the recorded EAT using the plot shown in Fig. 2. In a generic case this value is significant when $\mathrm{EAT}>65^{\circ} \mathrm{F}$.

$$
\begin{aligned}
& B=\left(A C R F P_{p}-A C R F P_{h}\right), \text { if } A C R F P_{p}>A C R F P_{h} \\
& B=0, \text { if } A C R F P_{p} \leq A C R F P_{h} \text { or EAT }<65^{\circ} \mathrm{F}
\end{aligned}
$$

Similar to the previous criteria, parameter B is plotted for the test case snippet, and Area_B represents the area under curve B. Therefore, minimum Area_B was considered the optimal HVAC criteria corresponding to the element ACRFP (PSI). 


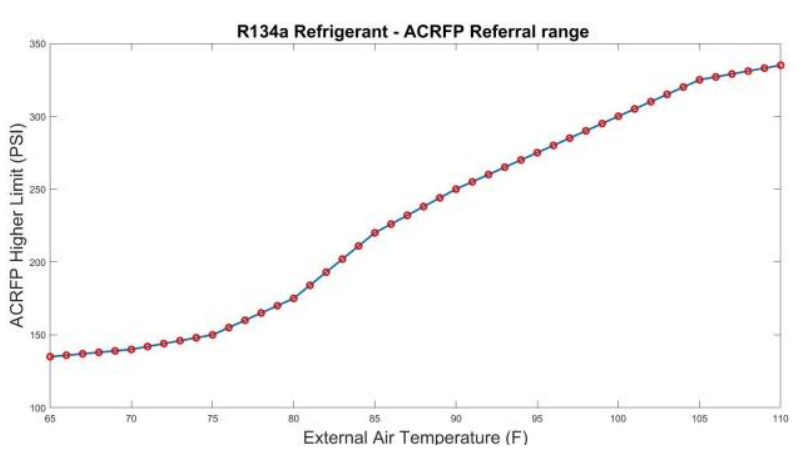

Fig. 2 : R134a ACS-ACRFP threshold curve

\subsection{Smoothness measure-EST and ACRFP}

In this research, we developed CATOP conformance vector Area $=[$ Area_A1 Area_A2 Area_B] plots for the test case snippets 100 steps $(1$ step $=10 \mathrm{~m})$. Along with the area under the curve, we considered the smoothness measure (S) for the plots [A1 A2 B] as the third optimal HVAC criterion. The spline fit was embedded into the curves [A1 A2 B] using the built-in functions of MATLAB [28].

\section{$\mathrm{S}=[\mathrm{R}$ Square, Adj R Square, SSE, RMSE]}

The vector $\mathrm{S}$ represents the smoothness performance fit measure vector estimated using the traditional statistical techniques Adj/R square and SSE/RMSE. R-squared is a statistical measure of how close the data are to the fitted regression line, whereas Adjusted R-squared is a modified version of R-squared adjusted for the number of predictors in the model, which is always lower than Rsquared. SSE is the residual sum of squares of the conformance between the predicted and fitted curve, and the square root of the mean SSE represents RMSE. Higher values of Adj/R square and lower SSE/RMSE were considered a good fit for the curve [28]. Adj/R square values range between [0 1$]$, representing the percentage of match, whereas SSE/RMSE have the same units of the parameters. Therefore, the vector $S$ is estimated individually for the plots [S_A1 S_A2 S_B] by fitting a spline using the built-in toolboxes of MATLAB. The mathematical models of vector $\mathrm{S}$ are not the scope of this article.

\section{Prediction of CAT}

In this approach, we challenged the constant CAT set by the user, and a novel model to predict optimal CAT profile in a definite user-defined range was developed. The default range of allowable CAT, $[6570]^{\circ} \mathrm{F}$ for EAT $>65^{\circ} \mathrm{F}$ and $\left[\begin{array}{ll}70 & 75\end{array}\right]^{\circ} \mathrm{F}$ for $\mathrm{EAT}<65^{\circ} \mathrm{F}$, are considered. In the following sections, we estimate the optimal CAT for future steps by following the process shown in Figure 3.

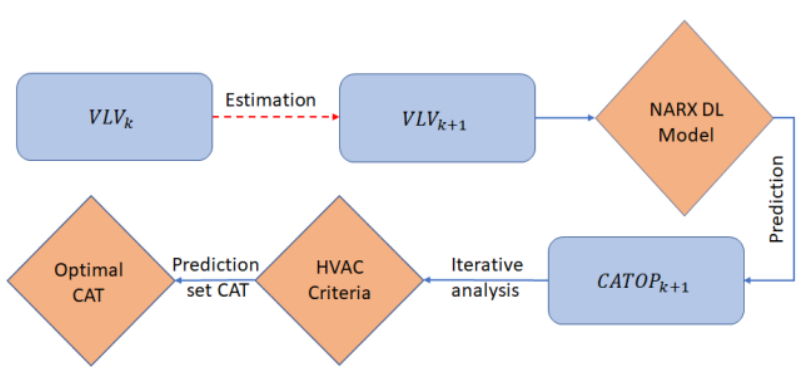

Fig. 3: Prediction of CAT - Proposed logic [28]

\subsection{Estimation of future inputs-NARX DL Model}

Step 1: We estimated the future input states $\left(V L V_{k+1}\right)$ of the DL model relative to the vehicle's current state $\left(V L V_{k}\right)$ by the equation set shown in Table 1 . The magnitude of the odometer reading $O_{k+1}(\mathrm{Km})$ and timestep $T_{k+1}(\mathrm{~s})$ is estimated using basic interpolation, and the vehicle's speed $S_{k+1}=\mathrm{SL}(\mathrm{MPH})$ since ACCSSP $\approx \mathrm{SL}$.

The parameters YAR $\left(Y_{a(k+l)}\right)$ and LAT $\left(L_{a(k+l)}\right)$ are estimated using the equations, framed assuming ISB [27], whereas as LOT $\left(L_{o(k+l)}\right)$ is calculated based on the vehicle resistance as shown in Table 1 . The vehicle is assumed to be integrated with infotainment and connectivity features, which assist our work to retrieve the terrain parameters $\left[R R C_{k+1}, \theta_{g(k+l)}\right]$, along with $E A T_{k+1}$ based on the GPS location and infotainment maps (e.g. Super and Ultra cruise features integrated into the Cadillac vehicle segment - GMC) [28].

We varied $C A T_{k+l}\left({ }^{\circ} \mathrm{F}\right)$ in a specific default range based on $E A T_{k+1}\left({ }^{\circ} \mathrm{F}\right)$. A sample set of the future input states $\left(V L V_{k+1}\right)$ of the DL model for 100 steps are presented in Table 2.

\subsection{Prediction of outputs-NARX DL Model}

Step 2: Six input sets $(1$ set $=1000 \mathrm{~m})$ are developed by varying the CAT in the user-defined range [65 70] ${ }^{\circ} \mathrm{F}$, based on step 1 . We fed the input sets into the NARX DL model and predicted the corresponding output sets (CATOP vectors). We adopted a similar procedure for the winter case scenario with $\mathrm{CAT}=[7075]^{\circ} \mathrm{F}$. The properties and precision of the prediction of the DL model are discussed in section 5.2.

\subsection{Implementation-HVAC criteria}

Step 3: We determined the corresponding CATOP conformance vector [A1 A2 B] by analysing the predicted output sets. The optimal HVAC criteria are applied, and we estimate the performance vector [Area R square Adj R SSE RMSE] for every set of outputs (Table 3). Based on these values, we identified the top three CAT's, satisfying the CATOP criteria for $100 \mathrm{~m}$ shown in Table 4 . Therefore, we framed the CAT matrix for $1000 \mathrm{~m}$ for two scenarios, as shown in Table 5.

\subsection{Estimation of optimal CAT}


Step 4: The CAT matrix (3X10) results in a maximum of $3^{10}$ possible CAT profiles for $1000 \mathrm{~m}$. In the final step, to identify the unique CAT profile, we proposed the following algorithm [28].

\section{Algorithm to estimate CAT}

1. Assuming the set CAT at step k was $C_{k}$, if the eligible CAT's were either $C_{k}+1, C_{k}$, or $C_{k}-1$, then the highest magnitude among the three was selected as $C_{k+1}$, for the case $E A T_{k} \geq 65^{\circ} \mathrm{F}$ and selected the lower value as $C_{k+1}$ for the case $E A T_{k}<65^{\circ} \mathrm{F}$.

2. We chose the value of $C_{k+1}$ closer to $C_{k}$. If this resulted in two values, the higher value was considered $C_{k+1}$ for the case $E A T_{k} \geq 65^{\circ} \mathrm{F}$, and the lower value for the case $E A T_{k}<65^{\circ} \mathrm{F}$.

3. If the eligible CATs were neither $C_{k}+1, C_{k}$ nor $C_{k}-1$, then $C_{k+1}=C_{k}$.

4. If $C_{k+1}=C_{k}$ for more than 1E3 steps ( $\left.1 \mathrm{step}=10 \mathrm{~m}\right)$, then $C_{k+1}=C_{k}+1$ for the case $E A T_{k} \geq 65^{\circ} \mathrm{F}$ or $C_{k^{-}}$ 1 for $E A T_{k}<65^{\circ} \mathrm{F}$.

\section{Computational analysis - Results}

\subsection{Data retrieval}

We conducted this research by obtaining a 2020 Cadillac CT5 test vehicle from GMC. A two-step procedure was employed to retrieve the data from the vehicle CAN bus [19]. As a first step, we connected the hardware neoVI to the vehicle and performed the data retrieval using the software Vehicle Spy [20]. This tool records data in realtime and allows the user to retrieve the selective signal data for analysis. We performed the real-time test procedure in the second step by activating the adaptive cruise control (ACC) feature, which enhances vehicle health [21]. The speed data were collected assuming a noslip scenario, i.e., traction produced is proportional to the friction coefficient and normal forces [22]. Also, we collected the snippets of data at a frequency of $10 \mathrm{~m}$ (odometer reading). This frequency was selected because the CAN bus would require at least $300 \mathrm{~ms}$ to record the change in CAT in steady state. We developed the test cases by driving the vehicle for two scenarios, EAT $>65$ ${ }^{\circ} \mathrm{F}$ (summer) and EAT $<45^{\circ} \mathrm{F}$ (winter). We adopted these two cases on selected road segments of freeways and state ways with a range of ACCSSP $=[5580] \mathrm{MPH}$, as shown in Figure 4. The properties of the datasets [mean, deviation, variance] of all the parameters retrieved are shown in Table 8.

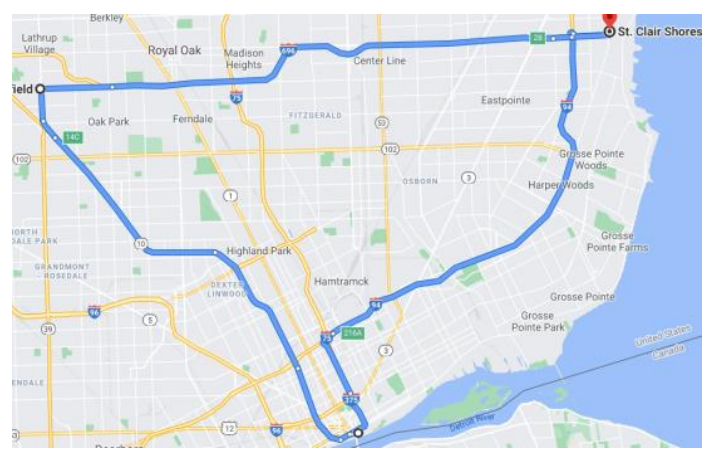

Fig. 4: Path traversed-Test cases 1 and 2.

\subsection{NARX DL model—Prediction of CATOP}

The data was retrieved from the GMC 2020 Cadillac CT5 vehicle in real-time and time dependent. Therefore, among many DL models, it is known from the existing literature that only three techniques, NARX, LSTM and ARIMA models, are widely used for time series prediction. We had tested the datasets in reference [14] using these techniques and concluded that the NARX DL model outperformed LSTM and ARIMA.

The NARX DL model is the simplest among all techniques, considering previous states (e.g. last three states) to predict the future state. This model is the linear representation of the dynamic system in discrete time with exogenous inputs. In section 2.1 , we proposed a novel set of inputs (VLV) and outputs (CATOP) to develop the supervised learning model. The DL model is developed using the datasets retrieved shown in Table 8, as described in section 5.1. The following mathematical model represents the linear model of NARX.

$$
\begin{aligned}
y(k)= & f(y(k-1), y(k-2), \cdots, y(k-n))+\ldots \\
& \sum_{i=1}^{m} g_{i}\left(u_{i}(k-1), u_{i}(k-2), \ldots, u_{i}(k-n)\right)
\end{aligned}
$$

\begin{tabular}{|l|l|}
\hline$y(k)$ & Output at timestep $\mathrm{k}$ \\
\hline$u_{i}(k)$ & Exogenous input at time step $\mathrm{k}$ \\
\hline$m$ & Number of exogenous inputs \\
\hline$n$ & Number of previous time states (e.g. $\mathrm{n}=3$ ) \\
\hline$\left[f g_{i}\right]$ & Generated functions based on training \\
\hline
\end{tabular}

In reference [14], we proved the performance of the NARX method with default training properties built-in MATLAB. The DL model is developed with an open network, two input/feedback delays and a fixed hidden layer $($ size $=10)$. The performance is validated using MSE, and the training function Levenberg-Marquardt backpropagation is used to develop the DL model. In this project, we focus our attention on presenting the concept of predicting CAT profile and developing detailed mathematical models is not the scope of our project. The software is provided by our sponsors and we used the relevant toolboxes in MATLAB to generate the training functions. 


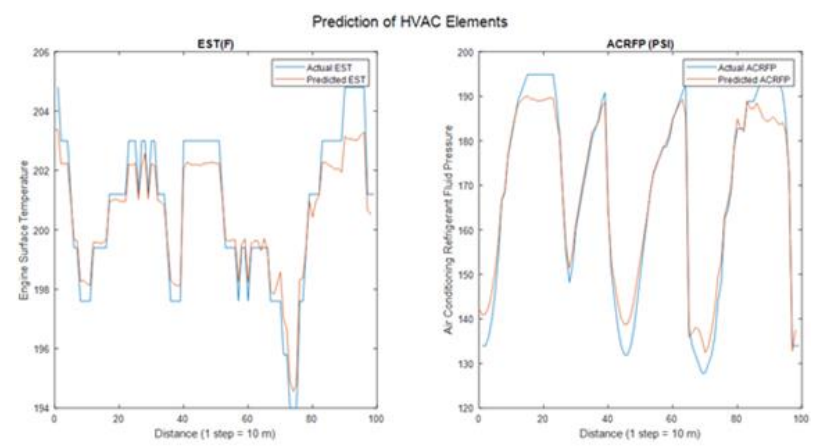

(a) $\mathrm{CAT}=68^{\circ} \mathrm{F}, \mathrm{EAT}=79.7^{\circ} \mathrm{F}$
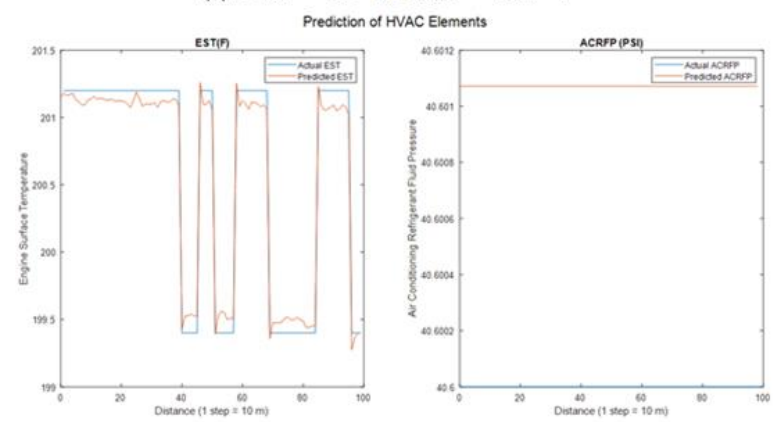

(b) $\mathrm{CAT}=72^{\circ} \mathrm{F}, \mathrm{EAT}=36.9^{\circ} \mathrm{F}$

Fig. 5: ACCSSP $=75 \mathrm{MPH}$ - Prediction of CATOP

The test cases with ACCSSP > $25 \mathrm{MPH}$ are selected, and individual training networks are developed for the two CATOP - elements. The results are shown in Figure 5 for two cases EAT $>65^{\circ} \mathrm{F}$ and EAT $<{ }^{\circ} \mathrm{F}$ for ACCSSP $=75$ MPH. Each figure consists of two parts, EST (left) and ACRFP (right). Furthermore, each plot compares the measured data (blue) with the predicted values (orange). Finally, we validated the DL model using the statistical measures (RMSE, FOD, SNR) by comparing the actual and predicted values of CATOP, reported in Table 6.

\subsection{Estimation of CAT}

The analysis is conducted on the datasets retrieved using steps mentioned in Section 4. The snippet with ACCSSP $=70 \mathrm{MPH}$, with EAT $=78.75^{\circ} \mathrm{F}$ and EAT $=38.3^{\circ} \mathrm{F}$, is applied with Steps 1-3, and the results are shown in Tables 2-5. We varied the range of initial CAT with the default values, and Figures $6 \mathrm{a}$ and $7 \mathrm{a}$ depict the possible CAT profiles resulting from Step 4. Therefore, constant initial CAT $=65^{\circ} \mathrm{F}$ and $70{ }^{\circ} \mathrm{F}$ results in unique CAT profiles shown in Figures $6 \mathrm{~b}$ and $7 \mathrm{~b}$. Similarly, the developed algorithm in MATLAB is applied to the test cases, and performance analysis is shown in Table 7 .

\section{Discussion}

This research consists of multiple concepts of developing the NARX DL model: mapping the elements VLV and CATOP (section 2.1), defining the optimal HVAC criteria, predicting optimal set CAT, and validation.

The efficacy of the DL model developed to predict CATOP vectors is validated using statistical techniques, shown in Table 6. The EST RMSE $<2.2$ for data set 1 and $<0.95$ for data set 2, whereas ACRFP FOD $<11$ for summer and $<0.94$ for winters. In real-time, the values of HVAC conformance vectors are always fluctuating, and hence the resulting SNR values are $<17$ for all cases, which depict acceptable noise. Despite the stochastic variation of the data, by visualising figure 5, we assume that the predicted values fit the real-time curves. A similar explanation follows for Figure 6 (Data set 2: winter data), and it is a well-known fact that extended training with multiple data sets would enhance the performance of the NARX DL model. Also, this article proposes the core concept of predicting the CAT profile by optimising CATOP elements. Therefore, the DL model is developed using default training properties and is assumed to produce acceptable results. Thus, we initiated the further steps of the project.

The test case snippets for ACCSSP $=70 \mathrm{MPH}$ are selected, and the proposed methodology is adapted to generate CAT profiles shown in Figures 6 and 7. The results of the performance analysis comparing the constant and predicted CAT profiles are shown in Table 7. The test case with ACCSSP $=75 \mathrm{MPH}, \mathrm{EAT}=84.398$ ${ }^{\circ} \mathrm{F}$, resulted in higher $\mathrm{EST}=246.732\left({ }^{\circ} \mathrm{F}\right)$ for constant CAT and predicted CAT profile has lower ACRFP = 782.45 (PSI), whereas, for EAT $=37.4{ }^{\circ} \mathrm{F}$, the predicted CAT has EST lower by $5.787\left({ }^{\circ} \mathrm{F}\right)$ and ACRFP has similar performance. The snippet with ACCSSP $=45$ $\mathrm{MPH}, \mathrm{EAT}=71.384^{\circ} \mathrm{F}$, resulted in ACRFP lower by 259.626 (PSI) for constant CAT, which is contradicting the proposed concept, but the smoothness performance is better for predicted CAT with higher [ R, Adj R] $=[0.977$ $0.944]$ and lower [SSE RMSE] $=[491.013 .540]$. It is easy to see that the performance of the predicted CAT profile with test case ACCSSP $=55 \mathrm{MPH}$ has enhanced performance for all the parameters, and a similar explanation follows for the rest of the scenarios.

\section{Conclusion and Future work}

In this manuscript, we developed a novel method to predict the set CAT. The supervised DL model was developed by mapping the elements VLV and CATOP. We validated the DL model by real-time datasets and applied statistical techniques to the conformance of predicted and actual values. Optimal HVAC criteria are defined for the element's EST and ACRFP to estimate a unique CAT for the future steps by utilising iterative methods, satisfying the user-defined range. The results obtained are satisfactory, and we quantified short snippets of distance $(1 \mathrm{E}+3 \mathrm{~m})$. Also, this method could derive a new functionality of inputting a range of user-defined set CAT to the HVAC system. Future work would involve developing the model to include all the affecting parameters and extend the validation using multiple vehicle test cases. 


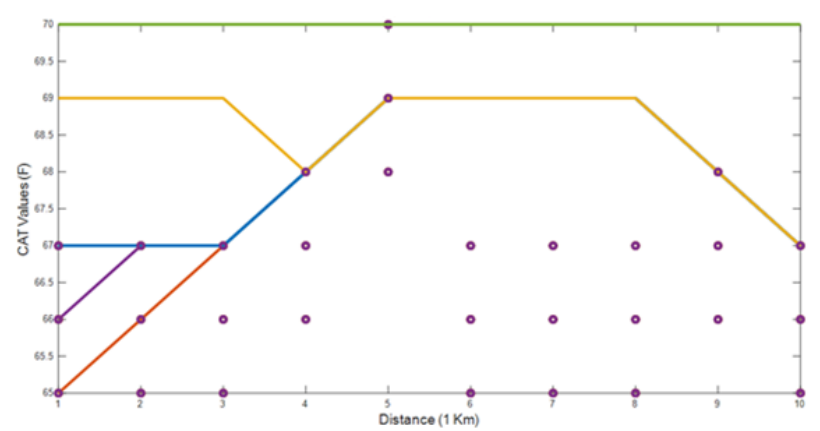

(a) CAT profiles - Initial CAT $=[6570]^{\circ} \mathrm{F}$

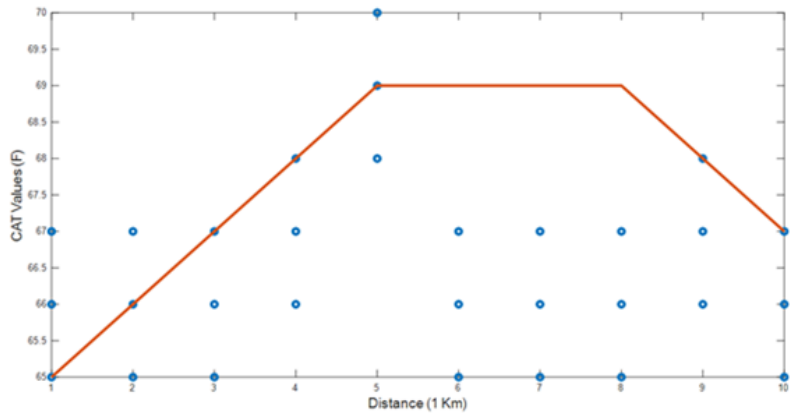

(b) CAT profiles $-\mathrm{CAT}=[65]^{\circ} \mathrm{F}$

Fig. $6:$ ACCSSP $=70 \mathrm{MPH}$; $\mathrm{EAT}=78.75^{\circ} \mathrm{F}$

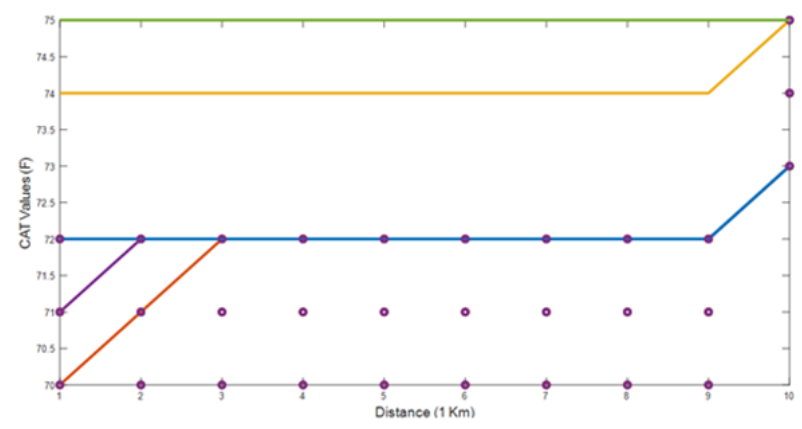

(a) CAT profiles - Initial $\mathrm{CAT}=[7075]^{\circ} \mathrm{F}$

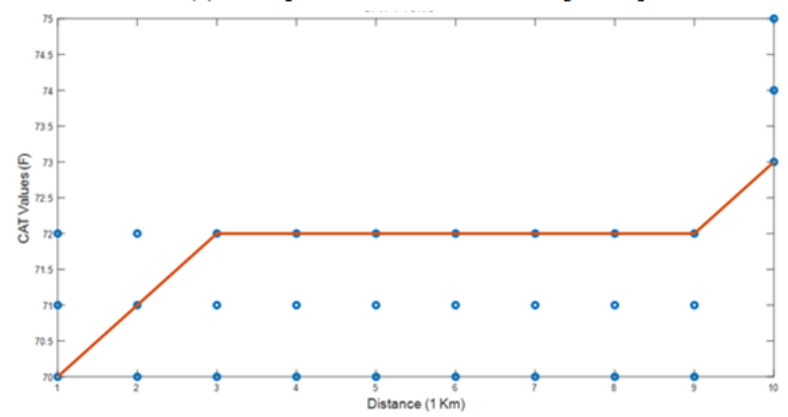

(b) CAT profiles - Initial $\mathrm{CAT}=[70]^{\circ} \mathrm{F}$

Fig. $7:$ ACCSSP $=70 \mathrm{MPH} ; \mathrm{EAT}=38.3^{\circ} \mathrm{F}$

\section{Additional information}

Supplementary Materials: The supplementary materials validating the model for multiple test cases are added for this article.

Author Contributions: The first author (Srikanth Kolachalama) came up with the idea, developed the concept, and performed the complete analysis. The second author (Dr Hafiz Malik) is the principal investigator for this project.

Funding: The project "Prediction of CAT" was performed under the research collaboration of the University of Michigan and GMC, funded by William J. Clifford (Director) of the Systems Engineering department at GMC.

Data Availability Statement: The data used in this work are proprietary to GMC and cannot be made publicly available. However, the modelling algorithm is available on request.

Acknowledgements: The authors would like to thank Iqbal Surti, Systems Engineer, for his assistance in realtime testing. The technical analysis was performed using the tools provided by GMC (Vehicle Spy and neoVI) and the University of Michigan (MATLAB).

Conflicts of Interest: None. The authors of this manuscript declare that there is no conflict of interest regarding the publication of this article.

\section{Abbreviations:}

\begin{tabular}{|c|l|}
\hline ACCSSP & Adaptive cruise control set speed profile (MPH) \\
\hline ACRFP & Air conditioning refrigerant fluid pressure (PSI) \\
\hline ACS & Air conditioning system \\
\hline CAN & Controller area network \\
\hline CAT & Cabin air temperature $\left({ }^{\circ} \mathrm{F}\right)$ \\
\hline CATOP & Cabin air temperature operating point \\
\hline DBV & Driver behaviour vector \\
\hline DL & Deep learning \\
\hline EAT & External air temperature $\left(^{\circ} \mathrm{F}\right)$ \\
\hline EOP & Engine operating point \\
\hline EST & Engine surface temperature $\left(^{\circ} \mathrm{F}\right)$ \\
\hline FOD & First-order derivative \\
\hline GMC & General Motors Company \\
\hline HVAC & Heating, ventilation, and air conditioning \\
\hline ISB & Ideal steering behaviour \\
\hline LAT & Lateral acceleration $\left(\right.$ m. $\left.s^{-2}\right)$ \\
\hline LOT & Longitudinal acceleration $\left(\mathrm{m} . \mathrm{s}^{-2}\right)$ \\
\hline MSE & Mean square error \\
\hline NARX & Nonlinear autoregressive method \\
\hline RMSE & Root mean square error \\
\hline RRC & Radius of road curvature $(\mathrm{m})$ \\
\hline SL & Speed limit $($ MPH) \\
\hline SNR & Signal to noise ratio \\
\hline SSE & Sum of squares of error \\
\hline VLV & Vehicle level vectors \\
\hline YAR & Yaw Rate (rad/s) \\
\hline
\end{tabular}

\section{Nomenclature:}

\begin{tabular}{|l|l|}
\hline$A_{c}$ & Area of vehicle cross-section $\left(\mathrm{m}^{2}\right)$ \\
\hline$C_{d}$ & Aerodynamic drag coefficient. 2020 Cadillac CT5 \\
\hline
\end{tabular}




\begin{tabular}{|c|c|}
\hline${ }^{\circ} \mathrm{C}$ & Centigrade \\
\hline${ }^{\circ} \mathrm{F}$ & Fahrenheit \\
\hline $\mathrm{g}$ & Gravity $\left(9.8 \mathrm{~m} . \mathrm{s}^{-2}\right)$ \\
\hline $\mathrm{Hz}$ & Hertz \\
\hline $\mathrm{Kg}$ & Kilogram \\
\hline $\mathrm{Km}$ & Kilometers \\
\hline$L_{a(k)}$ & Lateral acceleration at time step $\mathrm{k}\left(\mathrm{m} . \mathrm{s}^{-2}\right)$ \\
\hline$L_{o(k)}$ & Longitudinal acceleration at time step $\mathrm{k}\left(\mathrm{m} . \mathrm{s}^{-2}\right)$ \\
\hline$M_{c}$ & Mass of the vehicle. 2020 Cadillac CT5 (Kg) \\
\hline$M_{L}$ & Mass of the additional load $(\mathrm{Kg})$ \\
\hline MPH & Miles per hour \\
\hline $\mathrm{m}$ & Meters \\
\hline$m^{2}$ & Meter square \\
\hline $\mathrm{m} \cdot \mathrm{s}^{-2}$ & Meters per second square. \\
\hline $\mathrm{ms}$ & Milli seconds \\
\hline$\mu_{r}$ & Rolling coefficient \\
\hline PSI & Pound per square inch \\
\hline $\mathrm{rad}$ & Radians \\
\hline $\mathrm{rad} / \mathrm{s}$ & Radians per second \\
\hline$R R C_{k}$ & Radius of road curvature at time step $\mathrm{k}(\mathrm{m})$ \\
\hline$\rho$ & Density of air $\left(\mathrm{kg} \cdot \mathrm{m}^{-3}\right)$ \\
\hline $\mathrm{s}$ & Seconds \\
\hline$T_{k}$ & Time step (s) \\
\hline$d T$ & Incremental time step. $(\sim 300 \mathrm{~ms})$ \\
\hline$\theta_{g(k)}$ & Gradient of the terrain at time step k (rad) \\
\hline$Y_{a(k)}$ & Yaw rate at time step $\mathrm{k}(\mathrm{rad} / \mathrm{s})$ \\
\hline
\end{tabular}

\section{References}

(1) Holweg, M. (2008). The evolution of competition in the automotive industry. In Build to order (pp. 1334). Springer, London.

(2) Farrington, R., \& Rugh, J. (2000). Impact of vehicle air-conditioning on fuel economy, tailpipe emissions, and electric vehicle range (No. NREL/CP-54028960). National Renewable Energy Lab., Golden, CO (US).

(3) Khayyam, H., Kouzani, A. Z., Hu, E. J., \& Nahavandi, S. (2011). Coordinated energy management of vehicle air conditioning system. Applied thermal engineering, 31(5), 750-764.

(4) Johnson, V. H. (2002). Fuel used for vehicle air conditioning: a state-by-state thermal comfort-based approach (No. 2002-01-1957). SAE Technical Paper.

(5) Lee, J., Kim, J., Park, J., \& Bae, C. (2013). Effect of the air-conditioning system on the fuel economy in a gasoline engine vehicle. Proceedings of the Institution of Mechanical Engineers, Part D: Journal of Automobile Engineering, 227(1), 66-77.

(6) Lee, J., Kim, J., Park, J., \& Bae, C. (2013). Effect of the air-conditioning system on the fuel economy in a gasoline engine vehicle. Proceedings of the Institution of Mechanical Engineers, Part D: Journal of Automobile Engineering, 227(1), 66-77.
(7) Khayyam, H. (2013). Adaptive intelligent control of vehicle air conditioning system. Applied Thermal Engineering, 51(1-2), 1154-1161.

(8) Nasution, H. (2008). Development of fuzzy logic control for vehicle air conditioning system. Telkomnika, 6(2), 73.

(9) Khayyam, H., Abawajy, J., \& Jazar, R. N. (2012). Intelligent energy management control of vehicle air conditioning system coupled with engine. Applied thermal engineering, 48, 211-224.

(10) Khayyam, H., Kouzani, A. Z., \& Hu, E. J. (2009, June). Reducing energy consumption of vehicle air conditioning system by an energy management system. In 2009 IEEE intelligent vehicles symposium (pp. 752-757). IEEE.

(11) Huang, K. D., Tzeng, S. C., Jeng, T. M., \& Chiang, W. D. (2006). Air-conditioning system of an intelligent vehicle-cabin. Applied Energy, 83(6), 545-557.

(12)Fayazbakhsh, M. A., \& Bahrami, M. (2013). Comprehensive modeling of vehicle air conditioning loads using heat balance method. SAE technical paper, 2013, 1507

(13) Cvok, I., Ratkovic, I., \& Deur, J. (2020). Optimization of control parameters of vehicle airconditioning system for maximum efficiency (No. 2020-01-1242). SAE Technical Paper.

(14) Kolachalama, S., \& Lakshmanan, S. (2021). Using Deep Learning to Predict the Engine Operating Point in Real-Time (No. 2021-01-0186). SAE Technical Paper.

(15)Wang, W., Xi, J., \& Chen, H. (2014). Modeling and recognizing driver behavior based on driving data: A survey. Mathematical Problems in Engineering, 2014.

(16) Kolachalama, S., Kuppa, K., Mattam, D. and Shukla, M., 2008, January. Thermal Analysis of Radiator Core in Heavy Duty Automobile. In Heat Transfer Summer Conference (Vol. 48487, pp. 123-127).

(17) Eathakota, V., Singh, A. K., Kolachalam, S., \& Krishna, K. M. (2010, September). Determination of optimally stable posture for force actuator based articulated suspension for rough terrain mobility. In FIRA RoboWorld Congress (pp. 154-161). Springer, Berlin, Heidelberg.

(18) Talom, H. L., \& Beyene, A. (2009). Heat recovery from automotive engine. Applied Thermal Engineering, 29(2-3), 439-444.

(19) Xing, W., Chen, H., \& Ding, H. (1999, September). The application of controller area network on vehicle. In Proceedings of the IEEE International Vehicle Electronics Conference (IVEC'99)(Cat. No. 99EX257) (pp. 455-458). IEEE.

(20) Gallardo, F. B. (2018). Extraction and Analysis of Car Driving Data Via OBD II. (Doctoral dissertation, Miguel Hernández University of Elche).

(21) Benmimoun, M., Pütz, A., Zlocki, A., \& Eckstein, L. (2012, September). Effects of acc and fcw on speed, fuel consumption, and driving safety. In 2012 IEEE 
Vehicular Technology Conference (VTC Fall) (pp. 16). IEEE.

(22) Eathakota, V.P., Kolachalama, S., Krishna, K.M. and Sanan, S., 2008. Optimal posture control for force actuator based articulated suspension vehicle for rough terrain mobility. In Advances in Mobile Robotics (pp. 760-767).

(23) Yan, X., Fleming, J., \& Lot, R. (2018). A/C energy management and vehicle cabin thermal comfort control. IEEE Transactions on Vehicular Technology, 67(11), 11238-11242.

(24) Roberts, A., Brooks, R., \& Shipway, P. (2014). Internal combustion engine cold-start efficiency: A review of the problem, causes and potential solutions. Energy Conversion and Management, 82, 327-350.

(25) Borman, G., \& Nishiwaki, K. (1987). Internal combustion engine heat transfer. Progress in energy and combustion science, 13(1), 1-46.

(26) Autozone: Air conditioning pressure chart. R134a Refrigerant.

(27) Kolachalama, S., Hay, CL., Mushtarin, T., Todd, N., Heitman, J., Hermiz, S., An Algorithm to Estimate Steering Behavior Using Vehicle Radius Of Curvature, 647068, Research Disclosure, Questel Ireland Ltd - March 2018.

(28) Kolachalama, S., \& Malik, H. (2021). Predictive Model of ACC Speed to Enhance Engine Operating Conditions. 


\section{LIST OF TABLES}

Table 1: Equation Set - Prediction of future input states and CATOP criteria.

\begin{tabular}{|c|c|c|c|c|}
\hline$T_{k+1}=T_{k}+d T(\mathrm{~s})$ & $O_{k+1}=\underset{(\mathrm{Km})}{O_{k}+S_{k} \cdot d T}$ & \multicolumn{2}{|c|}{$E A T_{k+1}=E A T_{k}\left({ }^{\circ} \mathrm{F}\right)$} & $S_{k+1}=S_{k}(\mathrm{MPH})$ \\
\hline \multicolumn{5}{|c|}{$L_{o(k+l)}=g \mu_{r}+g \sin \left(\theta_{(k+l) g)}\right)+\frac{\rho C_{d} \cdot A_{c}}{2 \cdot\left(M_{c}+M_{L}\right)} \cdot S_{k+1}^{2}\left(\mathrm{~m} \cdot s^{-2}\right)$} \\
\hline \multicolumn{5}{|c|}{$2 R R C_{k+1}=\frac{S_{k+1}^{2}}{L_{a(k+l)}}+\frac{S_{k+1}}{Y_{a(k+1)}}, \min \left[\operatorname{abs}\left(Y_{a(k+1)} \cdot S_{k+1}-L_{a(k+1)}\right)\right]$} \\
\hline $\mathrm{g}=9.81 \mathrm{~m} \cdot \mathrm{s}^{-2}$ & $\mu_{r}=0.013$ & $\rho=1.225 \mathrm{~kg} \cdot \mathrm{m}^{-3}$ & $C_{d}=0.31$ & $A_{c}=1.71 \mathrm{~m}^{2}$ \\
\hline \multicolumn{2}{|c|}{$C A T_{k+1}=[6570]\left({ }^{\circ} \mathrm{F}\right)$ or $[7075]\left({ }^{\circ} \mathrm{F}\right)$} & \multicolumn{3}{|c|}{2020 Cadillac CT5: $M_{c}=1769.69 \mathrm{~kg}, M_{L}=78.7 \mathrm{~kg}(\mathrm{Load})$} \\
\hline
\end{tabular}

Table 2: Estimation of Future Inputs-DL Model, 2020 Cadillac CT5 (100 steps = $1000 \mathrm{~m})$

\begin{tabular}{|c|c|c|c|c|c|c|c|c|}
\hline Step & $\begin{array}{c}\text { Odometer } \\
(\mathbf{K m})\end{array}$ & $\begin{array}{l}\text { Speed } \\
\text { (MPH) }\end{array}$ & $\begin{array}{c}\mathbf{R R C} \\
(\mathbf{m})\end{array}$ & $\begin{array}{c}\mathbf{Y A R} \\
(\mathbf{r a d} / \mathbf{s})\end{array}$ & $\begin{array}{c}\text { LAT } \\
\left(\mathrm{m} . \mathrm{s}^{-2}\right)\end{array}$ & $\begin{array}{c}\text { LOT } \\
\left(\mathrm{m} . \mathrm{s}^{-2}\right)\end{array}$ & $\begin{array}{l}\text { EAT } \\
\left({ }^{\circ} \mathrm{F}\right)\end{array}$ & $\begin{array}{c}\text { CAT } \\
\left({ }^{\circ} \mathrm{F}\right)\end{array}$ \\
\hline$D_{0}$ & 15000 & 70 & 8304.140 & 0.216 & 0.1179 & 0.4375 & $78.5,38.3$ & {$[65$ 70], [70 75] } \\
\hline$d D_{10}$ & 15000.1 & 70 & 8304.140 & 0.216 & 0.1179 & 0.375 & $78.5,38.3$ & {$[6570],[7075]$} \\
\hline$d D_{20}$ & 15000.2 & 70 & 8304.140 & 0.216 & 0.1179 & 0.3125 & $78.5,38.3$ & {$[6570],[7075]$} \\
\hline$d D_{30}$ & 15000.3 & 70 & 9342.157 & 0.192 & 0.1048 & -0.125 & $78.5,38.3$ & {$[6570],[7075]$} \\
\hline$d D_{40}$ & 15000.4 & 70 & 24912.42 & 0.072 & 0.0393 & -0.1875 & $78.5,38.3$ & {$[6570],[7075]$} \\
\hline$d D_{50}$ & 15000.5 & 70 & 74737.261 & 0.024 & 0.0131 & -0.0625 & $78.5,38.3$ & {$[6570],[7075]$} \\
\hline$d D_{60}$ & 15000.6 & 70 & 74737.261 & 0.024 & 0.0131 & 0.25 & $78.5,38.3$ & {$[6570],[7075]$} \\
\hline$d D_{70}$ & 15000.7 & 70 & 37368.630 & 0.048 & 0.0262 & 0.25 & $78.5,38.3$ & {$[6570],[7075]$} \\
\hline$d D_{80}$ & 15000.8 & 70 & 24912.420 & 0.072 & 0.0393 & 0.1875 & $78.5,38.3$ & {$[6570],[7075]$} \\
\hline$d D_{90}$ & 15000.9 & 70 & 24912.420 & 0.072 & 0.0393 & 0.1875 & $78.5,38.3$ & {$[6570],[7075]$} \\
\hline$D_{100}$ & 15001 & 70 & 9342.157 & 0.192 & 0.1048 & 0.3125 & $78.5,38.3$ & {$[6570],[7075]$} \\
\hline
\end{tabular}

Table 3: Iterative Analysis_-DL Model, 2020 Cadillac CT5 (10 steps = $100 \mathrm{~m})$

\begin{tabular}{|c|c|c|c|c|c|c|c|c|c|c|c|c|c|c|c|}
\hline \multirow{2}{*}{$\frac{\text { CAT }}{{ }^{\circ} \mathrm{F}}$} & \multicolumn{5}{|c|}{ A1 } & \multicolumn{5}{|c|}{ A2 } & \multicolumn{5}{|c|}{$\mathbf{B}$} \\
\hline & Area & $\mathrm{R}$ & Adj R & $\mathrm{SSE}$ & RMSE & Area & $\mathrm{R}$ & Adj R & SSE & RMSE & Area & $\mathrm{R}$ & Adj R & SSE & RMSE \\
\hline \multicolumn{16}{|c|}{ ACCSSP $=70 \mathrm{MPH} ; \mathrm{EAT}=78.75^{\circ} \mathrm{F}$} \\
\hline 65 & 114.5 & 0.994 & 0.986 & 1.495 & 0.194 & 1931 & 0.998 & 0.994 & 61.03 & 1.242 & 2252 & 0.995 & 0.989 & 158.9 & 2.004 \\
\hline 66 & 175.2 & 0.995 & 0.987 & 2.749 & 0.264 & 1994 & 0.998 & 0.994 & 64.36 & 1.275 & 2365 & 0.996 & 0.989 & 167.8 & 2.059 \\
\hline 67 & 216.5 & .992 & 0.979 & 6.555 & \begin{tabular}{|l|}
0.407 \\
\end{tabular} & 2020 & 0.998 & 0.994 & 67.47 & 1.306 & 2379 & 0.996 & 0.990 & 149.4 & 1.943 \\
\hline 68 & 203.8 & 0.992 & 0.981 & 5.391 & 0.369 & 1872 & 0.997 & 993 & 67.63 & 1.307 & 2399 & 0.996 & 0.990 & 155.5 & 1.983 \\
\hline 69 & 178.2 & 0.993 & 0.982 & 3.933 & 0.315 & 1688 & 0.997 & 0.993 & 52.16 & 1.148 & 2402 & 0.996 & 0.990 & 167.6 & 2.058 \\
\hline 70 & 201.9 & 0.995 & 0.986 & 3.773 & 0.309 & 1612 & 0.998 & 0.994 & 44.56 & 1.061 & 2416 & 0.996 & 0.990 & 162.6 & 2.027 \\
\hline \multicolumn{16}{|c|}{$\mathrm{ACCSSP}=70 \mathrm{MPH} ; \mathrm{EAT}=38.3^{\circ} \mathrm{F}$} \\
\hline 70 & 47.069 & 0.990 & 0.976 & 0.551 & 0.118 & 40.095 & 0.987 & 0.968 & 0.938 & 0.154 & 0.000 & 0.000 & 0.000 & 0.000 & 0.000 \\
\hline 71 & 45.876 & 0.990 & 0.975 & 0.557 & 0.119 & 40.662 & 0.987 & 0.968 & 0.961 & 0.156 & 0.000 & 0.000 & 0.000 & 0.000 & 0.000 \\
\hline 72 & 45.408 & 0.990 & 0.975 & 0.561 & 0.119 & 41.013 & 0.987 & 0.968 & 0.978 & 0.157 & 0.000 & 0.000 & 0.000 & 0.000 & 0.000 \\
\hline 73 & 45.575 & 0.990 & 0.975 & 0.566 & 0.120 & 41.169 & \begin{tabular}{|l}
0.987 \\
\end{tabular} & 0.968 & 0.988 & 0.158 & 0.000 & 0.000 & 0.000 & 0.000 & 0.000 \\
\hline 74 & 46.270 & 0.990 & 0.975 & 0.569 & 0.120 & 41.162 & 0.987 & 0.968 & 0.993 & 0.158 & 0.000 & 0.000 & 0.000 & 0.000 & 0.000 \\
\hline 75 & 47.368 & 0.990 & 0.975 & 0.572 & 0.120 & 41.026 & 0.987 & 0.967 & 0.993 & 0.158 & 0.000 & 0.000 & 0.000 & 0.000 & 0.000 \\
\hline
\end{tabular}

Table 4: Eligible CAT Values: Iterative Analysis-Optimal CATOP. $(10$ steps $=100 \mathrm{~m})$

\begin{tabular}{|c|c|c|c|c|c|c|c|c|c|c|c|c|c|c|}
\hline \multicolumn{5}{|c|}{ A1 } & \multicolumn{5}{|c|}{ A2 } & \multicolumn{5}{|c|}{ B } \\
\hline Area & $\mathrm{R}$ & Adj R & SSE & RMSE & Area & $\mathrm{R}$ & $\operatorname{Adj} R$ & SSE & RMSE & Area & $\mathrm{R}$ & $\operatorname{Adj} R$ & SSE & RMSE \\
\hline & & & & & $\mathrm{CCS}$ & & МРH; & $\mathrm{AT}=$ & $78.75^{\circ} \mathrm{F}$ & & & & & \\
\hline
\end{tabular}




\begin{tabular}{|l|l|l|l|l|l|l|l|l|l|l|l|l|l|l|}
\hline 65 & 66 & 66 & 65 & 65 & 70 & 66 & 66 & 70 & 70 & 70 & 67 & 67 & 67 & 67 \\
\hline 66 & 70 & 70 & 66 & 66 & 69 & 65 & 65 & 69 & 69 & 69 & 68 & 68 & 68 & 68 \\
\hline 69 & 65 & 65 & 70 & 70 & 68 & 67 & 67 & 65 & 65 & 68 & 70 & 70 & 65 & 65 \\
\hline \multicolumn{10}{|c|}{ ACCSSP $=\mathbf{7 0}$ MPH; EAT = 38.3 ${ }^{\circ} \mathbf{F}$} \\
\hline 72 & 70 & 70 & 70 & 70 & 70 & 71 & 71 & 70 & 70 & 70 & 70 & 70 & 70 & 70 \\
\hline 73 & 71 & 71 & 71 & 71 & 71 & 70 & 70 & 71 & 71 & 71 & 71 & 71 & 71 & 71 \\
\hline 71 & 72 & 72 & 72 & 72 & 72 & 72 & 72 & 72 & 72 & 72 & 72 & 72 & 72 & 72 \\
\hline
\end{tabular}

Table 5: ACCSSP = 70 MPH: Optimal CAT Matrix- $(100$ steps $=1 \mathrm{~km})$

\begin{tabular}{|c|c|c|c|c|c|c|c|c|c|c|c|c|c|c|c|c|c|c|c|}
\hline \multicolumn{20}{|c|}{ CAT Matrix } \\
\hline \multicolumn{10}{|c|}{ EAT $=78.75\left({ }^{\circ} \mathrm{F}\right)$} & \multicolumn{10}{|c|}{ EAT $=38.3\left({ }^{\circ} \mathrm{F}\right)$} \\
\hline$d T_{1}$ & $d T_{2}$ & $d T_{3}$ & $\overline{\mathrm{d} T_{4}}$ & $\overline{\mathrm{d} T_{5}}$ & $d T_{6}$ & $d T_{7}$ & $d T_{8}$ & $d T_{9}$ & $d T_{10}$ & $d T_{1}$ & $d T_{2}$ & $d T_{3}$ & $\overline{\mathrm{d} T_{4}}$ & $\mathrm{~d} T_{5}$ & $\overline{d T_{6}}$ & $d T_{7}$ & $d T_{8}$ & $d T_{9}$ & $d T_{10}$ \\
\hline 66 & 66 & 66 & 68 & 68 & 65 & 66 & 66 & 68 & 66 & 70 & 70 & 70 & 70 & 70 & 70 & 72 & 70 & 71 & 73 \\
\hline 67 & 67 & 67 & 66 & 69 & 66 & 67 & 67 & 66 & 67 & 71 & 71 & 71 & 71 & 71 & 71 & 70 & 71 & 72 & 74 \\
\hline 65 & 65 & 65 & 67 & 70 & 67 & 65 & 65 & 67 & 65 & 72 & 72 & 72 & 72 & 72 & 72 & 71 & 72 & 70 & 75 \\
\hline
\end{tabular}

Table 6: NARX Model Performance-ACC Speeds [35 75] MPH

\begin{tabular}{|c|c|c|c|c|c|c|c|c|}
\hline \multirow{2}{*}{\multicolumn{3}{|c|}{ (Date: June 16, 2020) }} & \multicolumn{6}{|c|}{$\begin{array}{c}\text { Data Set 1 : NARX-DL Model Validation (Error = Predicted - } \\
\text { Actual) }\end{array}$} \\
\hline & & & \multicolumn{3}{|c|}{ EST $\left({ }^{\circ} \mathrm{F}\right)$} & \multicolumn{3}{|c|}{ ACRFP (PSI) } \\
\hline $\begin{array}{l}\text { ACCSSP } \\
(\mathrm{MPH})\end{array}$ & $\mathrm{CAT}\left({ }^{\circ} \mathrm{F}\right)$ & EAT $\left({ }^{\circ} \mathrm{F}\right)$ & RMSE & FOD & SNR & RMSE & FOD & SNR \\
\hline 35 & 66 & 83.309 & 2.2057 & 1.5868 & 5.1067 & 14.0017 & 10.5611 & 16.1348 \\
\hline 45 & 65 & 80.375 & 1.8169 & 1.4288 & 7.1183 & 10.8150 & 7.4388 & 12.1116 \\
\hline 55 & 68 & 82.526 & 1.4794 & 1.0503 & 5.2231 & 9.5438 & 7.2012 & 20.3788 \\
\hline 65 & 67 & 81.32 & 1.66 & 1.2953 & 12.7934 & 3.7248 & 2.7151 & 6.9461 \\
\hline 75 & 70 & 86.081 & 1.2763 & 0.7945 & 5.7699 & 8.6413 & 5.2471 & 28.3001 \\
\hline \multirow{2}{*}{\multicolumn{3}{|c|}{ (Date: February 25, 2021) }} & \multicolumn{6}{|c|}{$\begin{array}{c}\text { Data Set 2 : NARX -DL Model Validation (Error = Predicted - } \\
\text { Actual) }\end{array}$} \\
\hline & & & \multicolumn{3}{|c|}{ EST $\left({ }^{\circ} \mathrm{F}\right)$} & \multicolumn{3}{|c|}{ ACRFP (PSI) } \\
\hline $\begin{array}{l}\text { ACCSSP } \\
(\mathrm{MPH})\end{array}$ & $\mathrm{CAT}\left({ }^{\circ} \mathrm{F}\right)$ & EAT $\left({ }^{\circ} \mathrm{F}\right)$ & RMSE & FOD & SNR & RMSE & FOD & SNR \\
\hline 35 & 76 & 36.374 & 0.9528 & 0.6636 & 3.4284 & 2.9186 & 0.9376 & 1.3323 \\
\hline 45 & 71 & 39.047 & 0.5678 & 0.3981 & 6.2342 & 0.0281 & 0.0148 & 1.7795 \\
\hline 55 & 73 & 33.8 & 0.3916 & 0.2618 & 5.4806 & 0.0040 & 0.0007 & 0.3951 \\
\hline 65 & 74 & 37.4 & 0.3080 & 0.2158 & 15.4239 & 0.0013 & 0.0007 & 1.3281 \\
\hline 75 & 75 & 37.4 & 0.4556 & 0.3179 & 32.7227 & 0.0011 & 0.000 & 0.000 \\
\hline
\end{tabular}

Table 7: Performance analysis-Prediction of CAT

\begin{tabular}{|c|c|c|c|c|c|c|c|c|}
\hline Parameter & EAT $\left({ }^{\circ} \mathrm{F}\right)$ & $\begin{array}{c}\text { CAT Profile } \\
\left({ }^{\circ} \mathrm{F}\right)\end{array}$ & Area & Conformance & $\mathbf{R}$ & $\operatorname{Adj} R$ & SSE & RMSE \\
\hline \multicolumn{9}{|c|}{ ACCSSP $=35$ MPH } \\
\hline \multirow{4}{*}{$\begin{array}{c}\text { EST } \\
{[\mathrm{A} 1, \mathrm{~A} 2]}\end{array}$} & \multirow[t]{2}{*}{78.566} & 66 & 515.975 & \multirow[t]{2}{*}{-9.312} & 0.960 & 0.900 & 2.981 & 0.276 \\
\hline & & Predicted & 506.662 & & 0.810 & 0.526 & 22.762 & 0.762 \\
\hline & \multirow[t]{2}{*}{36.806} & 74 & 424.360 & \multirow[t]{2}{*}{4.411} & 0.989 & 0.973 & 12.604 & 0.567 \\
\hline & & Predicted & 428.771 & & 0.992 & 0.980 & 11.889 & 0.551 \\
\hline \multirow{4}{*}{$\begin{array}{c}\text { ACRFP } \\
\text { (B) }\end{array}$} & \multirow[t]{2}{*}{78.566} & 66 & 1957.947 & \multirow[t]{2}{*}{-20.879} & 0.985 & 0.962 & 732.229 & 4.323 \\
\hline & & Predicted & 1937.067 & & 0.983 & 0.958 & 810.917 & 4.550 \\
\hline & \multirow[t]{2}{*}{36.806} & 74 & 28924.676 & \multirow[t]{2}{*}{-4.548} & 0.982 & 0.954 & 1.384 & 0.188 \\
\hline & & Predicted & 28920.127 & & 0.985 & 0.962 & 1.121 & 0.169 \\
\hline \multicolumn{9}{|c|}{$\mathrm{ACCSSP}=45 \mathrm{MPH}$} \\
\hline & 71.384 & 65 & 350.128 & -54.605 & 0.974 & 0.934 & 11.985 & 0.553 \\
\hline
\end{tabular}




\begin{tabular}{|c|c|c|c|c|c|c|c|c|}
\hline \multirow{3}{*}{$\begin{array}{c}\text { EST } \\
{[\mathrm{A} 1, \mathrm{~A} 2]}\end{array}$} & & Predicted & 295.523 & & 0.981 & 0.952 & 8.216 & 0.458 \\
\hline & \multirow[t]{2}{*}{33.8} & 71 & 8.335 & \multirow[t]{2}{*}{-4.436} & 0.997 & 0.994 & 0.000 & 0.000 \\
\hline & & Predicted & 3.898 & & 0.984 & 0.959 & 0.002 & 0.007 \\
\hline \multirow{4}{*}{$\begin{array}{c}\text { ACRFP } \\
\text { (B) }\end{array}$} & \multirow[t]{2}{*}{71.384} & 65 & 968.488 & \multirow[t]{2}{*}{259.626} & 0.915 & 0.788 & 845.487 & 4.646 \\
\hline & & Predicted & 1228.114 & & 0.977 & 0.944 & 491.012 & 3.540 \\
\hline & \multirow[t]{2}{*}{33.8} & 71 & 29057.213 & \multirow[t]{2}{*}{0.462} & 0.998 & 0.996 & 0.000 & 0.000 \\
\hline & & Predicted & 29057.675 & & 0.887 & 0.717 & 0.000 & 0.002 \\
\hline \multicolumn{9}{|c|}{ ACCSSP $=55 \mathrm{MPH}$} \\
\hline \multirow{4}{*}{$\begin{array}{c}\text { EST } \\
{[\mathrm{A} 1, \mathrm{~A} 2]}\end{array}$} & \multirow[t]{2}{*}{70.997} & 65 & 658.373 & \multirow[t]{2}{*}{-72.241} & 0.969 & 0.922 & 4.957 & 0.356 \\
\hline & & Predicted & 586.131 & & 0.969 & 0.924 & 5.472 & 0.374 \\
\hline & \multirow[t]{2}{*}{33.8} & 73 & 307.908 & \multirow[t]{2}{*}{-1.912} & 0.967 & 0.917 & 1.839 & 0.217 \\
\hline & & Predicted & 305.996 & & 0.965 & 0.913 & 1.867 & 0.218 \\
\hline \multirow{4}{*}{$\begin{array}{c}\text { ACRFP } \\
\text { (B) }\end{array}$} & \multirow[t]{2}{*}{70.997} & 65 & 2928.211 & \multirow[t]{2}{*}{-229.571} & 0.970 & 0.925 & 2745.421 & 8.371 \\
\hline & & Predicted & 2698.639 & & 0.974 & 0.936 & 2679.109 & 8.270 \\
\hline & \multirow[t]{2}{*}{33.8} & 73 & 28850.426 & \multirow[t]{2}{*}{-2.175} & 0.999 & 0.998 & 0.000 & 0.000 \\
\hline & & Predicted & 28848.251 & & 0.997 & 0.993 & 0.000 & 0.001 \\
\hline \multicolumn{9}{|c|}{$\mathrm{ACCSSP}=65 \mathrm{MPH}$} \\
\hline \multirow{4}{*}{$\begin{array}{c}\text { EST } \\
{[\mathrm{A} 1, \mathrm{~A} 2]}\end{array}$} & \multirow[t]{2}{*}{81.095} & 67 & 505.586 & \multirow[t]{2}{*}{-31.343} & 0.978 & 0.944 & 7.887 & 0.449 \\
\hline & & Predicted & 474.242 & & 0.948 & 0.871 & 22.979 & 0.766 \\
\hline & \multirow[t]{2}{*}{37.4} & 72 & 568.740 & \multirow[t]{2}{*}{4.009} & 0.970 & 0.924 & 1.279 & 0.181 \\
\hline & & Predicted & 572.750 & & 0.968 & 0.921 & 1.292 & 0.182 \\
\hline \multirow{4}{*}{$\begin{array}{c}\text { ACRFP } \\
\text { (B) }\end{array}$} & \multirow[t]{2}{*}{81.095} & 67 & 3078.741 & \multirow[t]{2}{*}{269.982} & 0.946 & 0.865 & 61.282 & 1.251 \\
\hline & & Predicted & 3348.724 & & 0.961 & 0.901 & 92.636 & 1.538 \\
\hline & 37.4 & 72 & 28851.571 & 0.180 & 0.912 & 0.779 & 0.000 & 0.000 \\
\hline & & Predicted & 28851.752 & & 0.989 & 0.971 & 0.000 & 0.000 \\
\hline & & & $\mathrm{ACCSS}$ & 75 МРН & & & & \\
\hline & 84.398 & 68 & 639.694 & 246.732 & 0.952 & 0.880 & 7.089 & 0.425 \\
\hline EST & & Predicted & 886.427 & & 0.952 & 0.879 & 28.418 & 0.852 \\
\hline$[\mathrm{A} 1, \mathrm{~A} 2]$ & 37.40 & 70 & 669.610 & -5.7879 & 0.966 & 0.915 & 2.408 & 0.248 \\
\hline & & Predicted & 663.822 & & 0.967 & 0.917 & 2.350 & 0.245 \\
\hline & 84.398 & 68 & 2231.887 & -782.45 & 0.919 & 0.797 & 383.320 & 3.128 \\
\hline ACRFP & & Predicted & 1449.436 & & 0.909 & 0.773 & 1664.53 & 6.518 \\
\hline (B) & 37.4 & 70 & 28850.316 & 0.065 & 0.999 & 0.996 & 0.000 & 0.000 \\
\hline & & Predicted & 28850.381 & & 0.925 & 0.813 & 0.000 & 0.000 \\
\hline
\end{tabular}

Table 8: Dataset sets—Real-time testing: 2020 Cadillac CT5

Dataset 1-Summer Data (Date: June 16, 2020)

\begin{tabular}{|c|c|c|c|c|c|c|}
\hline Parameters & \multicolumn{3}{|c|}{ ACC Speed [25 55] MPH } & \multicolumn{2}{c|}{ ACC Speed [55 85] MPH } \\
\hline Inputs & Mean & StdDev & Variation & Mean & StdDev & Variation \\
\hline Odometer $(\mathrm{km})$ & 16047.528 & 36.052 & 0.002 & 14774.200 & 707.602 & 0.048 \\
\hline Speed $(\mathrm{MPH})$ & 39.342 & 8.948 & 0.227 & 64.739 & 6.843 & 0.106 \\
\hline Acceleration $\left(\mathrm{m} . \mathrm{s}^{-2}\right)$ & 0.522 & 0.551 & 1.055 & 0.010 & 0.380 & 37.080 \\
\hline LOT $\left(\mathrm{m} . \mathrm{s}^{-2}\right)$ & 0.332 & 0.529 & 1.591 & -0.172 & 0.383 & -2.234 \\
\hline LAT $\left(\mathrm{m} . \mathrm{s}^{-2}\right)$ & 0.457 & 0.523 & 1.145 & 0.249 & 0.320 & 1.284 \\
\hline YAR $(\mathrm{deg} / \mathrm{sec})$ & 0.018 & 0.036 & 1.998 & -0.067 & 0.726 & -10.784 \\
\hline EAT $\left({ }^{\circ} \mathrm{F}\right)$ & 71.585 & 1.929 & 0.027 & 80.142 & 5.118 & 0.064 \\
\hline CAT $\left({ }^{\circ} \mathrm{F}\right)$ & 82.800 & 4.856 & 0.059 & 66.922 & 1.719 & 0.026 \\
\hline Outputs & Mean & Deviation & Variation & Mean & Deviation & Variation \\
\hline EST $\left({ }^{\circ} \mathrm{F}\right)$ & 198.931 & 2.649 & 0.013 & 195.183 & 17.056 & 0.087 \\
\hline ACRFP $(\mathrm{PSI})$ & 160.584 & 22.056 & 0.137 & 165.131 & 21.673 & 0.131 \\
\hline
\end{tabular}

Dataset 2- Winter Data (Date: February 25, 2021) 


\begin{tabular}{|c|c|c|c|c|c|c|}
\hline Parameters & \multicolumn{2}{|c|}{ ACC Speed [25 55] MPH } & \multicolumn{3}{c|}{ ACC Speed [55 85] MPH } \\
\hline Inputs & Mean & StdDev & Variation & Mean & StdDev & Variation \\
\hline Odometer $(\mathrm{km})$ & 24875.333 & 10.030 & 0.000 & 24785.630 & 5.258 & 0.000 \\
\hline Speed $(\mathrm{MPH})$ & 42.973 & 7.216 & 0.168 & 68.626 & 6.253 & 0.091 \\
\hline Acceleration $\left(\mathrm{m} . \mathrm{s}^{-2}\right)$ & 0.004 & 0.429 & 118.764 & 0.010 & 0.105 & 10.725 \\
\hline LOT $\left(\mathrm{m} . \mathrm{s}^{-2}\right)$ & -0.165 & 0.443 & -2.677 & -0.158 & 0.158 & -1.000 \\
\hline LAT $\left(\mathrm{m} . \mathrm{s}^{-2}\right)$ & 0.159 & 0.252 & 1.581 & 0.066 & 0.193 & 2.910 \\
\hline YAR $(\mathrm{deg} / \mathrm{sec})$ & -0.114 & 0.397 & -3.492 & -0.083 & 0.285 & -3.443 \\
\hline EAT $\left({ }^{\circ} \mathrm{F}\right)$ & 39.849 & 0.870 & 0.022 & 36.383 & 0.914 & 0.025 \\
\hline CAT $\left({ }^{\circ} \mathrm{F}\right)$ & 74.436 & 7.293 & 0.098 & 77.420 & 5.449 & 0.070 \\
\hline Outputs & Mean & Deviation & Variation & Mean & Deviation & Variation \\
\hline EST $\left({ }^{\circ} \mathrm{F}\right)$ & 201.779 & 3.994 & 0.020 & 201.033 & 4.350 & 0.022 \\
\hline ACRFP $(\mathrm{PSI})$ & 47.309 & 3.417 & 0.072 & 40.335 & 0.684 & 0.017 \\
\hline
\end{tabular}

